\title{
Anabases
}

ANABASES Traditions et réceptions de l'Antiquité

19 | 2014

Varia

\section{Véronique KRINGS \& François PUGNIÈRE (éd.), Nîmes et ses Antiquités. Un passé présent $\mathrm{XVI}^{e}-\mathrm{XI} \mathrm{X}^{e}$ siècle}

\section{Germaine Aujac}

\section{OpenEdition}

Journals

Édition électronique

URL : http://journals.openedition.org/anabases/4743

DOI : $10.4000 /$ anabases. 4743

ISSN : 2256-9421

\section{Éditeur}

E.R.A.S.M.E.

\section{Édition imprimée}

Date de publication : 1 avril 2014

Pagination : 353-354

ISSN : 1774-4296

\section{Référence électronique}

Germaine Aujac, « Véronique krings \& François pugnière (éd.), Nîmes et ses Antiquités. Un passé présent XVI $l^{e}$-xIX siècle », Anabases [En ligne], 19 | 2014, mis en ligne le 01 avril 2014, consulté le 10 décembre 2020. URL : http://journals.openedition.org/anabases/4743; DOI : https://doi.org/10.4000/anabases 4743

Ce document a été généré automatiquement le 10 décembre 2020.

(c) Anabases 


\title{
Véronique KRINGS \& François PUGNIÈRE (éd.), Nîmes et ses Antiquités. Un passé présent XVI ${ }^{e}-X^{e}{ }^{e}$ siècle
}

\author{
Germaine Aujac
}

\section{RÉFÉRENCE}

Véronique KRINGS \& François PUGNIÈRE (éd.), Nîmes et ses Antiquités. Un passé présent XVI XIX siècle, Bordeaux, Ausonius Éditions, 2013, 335 p.

30 euros / ISBN 978-2-35613-082-2, ISSN 1298-1990

1 C'est un très savant ouvrage que viennent de procurer ses éditeurs sur les vicissitudes de la Nîmes romaine au cours des siècles considérés. Une carte fort claire, en début d'ouvrage, montre les diverses enceintes de la ville, dont celle d'Auguste dont les restes sont encore visibles. Dans ses propos liminaires, F. Pugnière, président de la Société d'Histoire moderne et contemporaine de Nîmes et du Gard, présente l'objectif de ce livre : utiliser les riches fonds d'archives pour restituer « le monde de la collection » et exposer les divers problèmes soulevés par la réception de l'Antiquité au cours du temps. En guise de Prologue, V. Krings établit un important glossaire définissant les termes les plus fréquemment utilisés, mais faisant aussi la part belle aux principaux monuments de Nîmes ou du Gard, sans oublier une mention particulière à JeanFrançois Séguier (1703-1784), le fondateur du plus ancien musée de Nîmes, un érudit tout dévoué à l'Antiquité et à sa ville.

2 L'ouvrage est divisé en quatre grandes parties. La première, intitulée Panorama, s'intéresse d'abord, sous la plume de G. Caillat, à La place des monuments antiques dans l'espace public à l'époque moderne : l'appropriation du patrimoine antique n'allait pas sans d'âpres discussions entre archéologues et pouvoirs publics. Odile Parsis-Barubé, pour sa part, décrit les Mutations du statut des « antiquités » dans la culture historienne en France, des Lumières au romantisme; elle en évoque les principaux acteurs au cours des siècles: 
Bernard de Montfaucon (1655-1741), le Comte de Caylus (1692-1765), à la fois collectionneur, mécène et curieux, Charles-Louis Clérisseau (1721-1820) dont les Antiquités de la France (1778) sont la dernière contribution de l'érudition d'Ancien Régime. La Révolution accorda une grande place aux "antiquités nationales »: l'archéologie fut alors promue au rang de science auxiliaire de l'histoire; sous la monarchie de Juillet, Guizot (1787-1874), ministre né à Nîmes, offrit aux antiquaires une reconnaissance institutionnelle, en un temps où l'archéologie allait s'allier à l'histoire.

3 Après ce vaste panorama, c'est Nîmes qui redevient la vedette dans les trois parties suivantes. On y rencontre tous ceux, érudits ou politiques, nîmois ou non, qui ont œuvré peu ou prou à la conservation de ce patrimoine exceptionnel. C'est Jean Poldo d'Albenas (1512-1563) dont le Discours Historial de l'antique et illustre cité de Nîmes (publié en 1559 et brillamment illustré) fit mieux connaître du public érudit les monuments romains, comme le souligne, dans cette seconde partie couvrant la période « De la Renaissance à l'âge classique ", Frédérique Lemerle (La réception des antiquités nîmoises de 1500 à 1660). Victor Lassalle illustre de suggestives images L'héritage de l'Antiquité dans l'architecture nîmoise de la Renaissance et de l'époque classique. Les rivalités peuvent aussi se faire jour entre villes voisines; ainsi Flore César et Marianne Freyssinet posent la question: Curiosité antiquaire (1600-1750): un antagonisme présupposé entre Nîmes et Montpellier? Mais c'est pour montrer la grande solidarité qui existe en fait entre les amoureux de l'Antiquité, que ce soit le collectionneur Montpelliérain François Rachin (1560-1641), le " prince des curieux » Nicolas-Claude Fabri de Peiresc (1580-1674), ou encore Léon Ménard, le célèbre auteur d'une Histoire civile, ecclésiastique et littéraire de la ville de Nîmes, publiée de 1744 à 1758.

François Pugnière inaugure la troisième partie consacrée au Siècle des Lumières avec une étude sur Antiquaires et Antiquité à Nîmes au Siècle des Lumières. L'un des plus actifs dans cette période fut Jean-François Séguier, passionné de numismatique et déchiffreur d'inscriptions (dont celle de la Maison Carrée, qui était une dédicace aux deux fils adoptifs de l'empereur Auguste). Non moins important fut L. Ménard, auteur d'une Histoire de Nîmes déjà citée. À la veille de la Révolution, l'Histoire abrégée de la ville de Nîmes de J.-F. Dieudonné de Maucomble, publiée en 1767 et rééditée en 1789, connut un vif succès, tandis que Clérisseau publiait en 1778 les Antiquités de la France. Non sans une pointe d'humour, Michel Christol présente Un faux épigraphique de l'abbé Folard: une perversion du goût? L'inscription inventée par l'abbé de Folard (1665-1748) attribuait à Antonin le Pieux l'adduction d'eau à Nîmes et le Pont du Gard, en un moment où l'approvisionnement en eau de Nîmes faisait question. Odile Cavalier, "Né pour former un cabinet comme La Fontaine pour écrire des fables". Les pagodes et marmousets du chanoine Pichony (1711-1785), attribue la paternité d'un grand recueil in-folio récemment acquis par le musée Calvet au fameux chanoine Joseph Pichony dont elle retrace la carrière, les relations avec le milieu des antiquisants (dont Esprit Calvet), et les circuits d'achat qui expliquent la richesse de son cabinet. Pierre Pinon se penche sur Les Antiquités de la France de Charles Louis Clérisseau (1721-1820) ; architecte de Catherine II, conseiller de Thomas Jefferson, Clérisseau, de retour en France, étudia les Antiquités du Midi de la France, en particulier celles de Nîmes. Quant à Pascal Trarieux, son article sur Les portraitistes de la maison Carrée est illustré de nombreuses et belles reproductions.

5 La quatrième partie porte sur le XIX ${ }^{\mathrm{e}}$ siècle. Françoise Bercé pose la question : Restaurer au XIX siècle? Le Nîmois Guizot avait créé en 1830 un poste d'Inspecteur général des Monuments historiques, d'abord occupé par Prosper Mérimée, qui, visitant le Midi de la 
France, attribua l'édification de la Maison Carrée à une période de décadence, ce qui lui valut la hargne des archéologues, dont Perrot. C'est d'ailleurs ce dernier que présente Pierre Tardat: Un antiquaire dans la "cité des Antonins», Jean François Aimé Perrot (1790-1867). Curieux personnage que ce collectionneur de momies égyptiennes qui, nommé en 1816 gardien de la Maison Carrée, soutint avec Séguier et contre Mérimée sa datation au siècle d'Auguste. Hélène Bocard, évoquant l'invention en 1839 du daguerréotype, présente avec un luxe d'illustrations, L'Antiquité photographiée : l'exemple de Nîmes (1840-1870).

Il revenait au grand savant Gilles Sauron de tirer les conclusions de cet ouvrage aussi érudit que varié. "C'est une enquête passionnante - écrit-il - que de suivre au fil du temps les étapes de l'appropriation d'un patrimoine aussi précieux par des esprits qui avaient encore tout à conquérir sur le terrain de la Science de l'Antiquité » (p. 311), et il conclut: " Nîmes est demeurée depuis la Renaissance la ville romaine dont la parure monumentale préserve à l'état natif l'apport de Rome à l'histoire de la beauté " (p. 314).

7 Une abondante bibliographie, un index des noms de personnes, les résumés des articles complètent heureusement cet important ouvrage qui donnera à ses lecteurs l'envie d'aller voir sur place les monuments romains d'une ville si attachante.

\section{AUTEURS}

\section{GERMAINE AUJAC}

Université de Toulouse (UTM)

aujac.germaine@wanadoo.fr 